\title{
Subversão da exclusão escolar via mediação em atividade de produção textual*
}

\author{
Wagner Rodrigues Silva \\ Universidade Federal do Tocantins, Campus Araguaína, Curso de Letras
}

\section{Introdução}

A exclusão escolar pode ser visibilizada pela incapacidade do aluno em realizar atividades tipicamente escolares no espaço da sala de aula, bem como pela sua inaptidão para agir com sucesso em situações sociais envolvendo o uso da língua escrita e falada. A primeira limitação é percebida facilmente pelos educadores em contexto de ensino, pois, devido a resquícios de práticas da tradição pedagógica, as habilidades necessárias para um bom desempenho escolar continuam sendo supervalorizadas. A segunda limitação apresentada ganha fôlego com as recentes discussões sobre práticas pedagógicas para o letramento,

* Versão ampliada e aprofundada do texto de minha autoria, "Subvertendo a exclusão escolar: a mediação como via para a aprendizagem e o desenvolvimento do aluno" (2005). O trabalho decorre das investigações referentes às práticas de reflexão sobre a escrita, desenvolvidas no âmbito do projeto integrado "Práticas de escrita e de reflexão sobre a escrita em contextos de ensino", apoiado pelo CNPq. propostas pelas diretrizes curriculares brasileiras vigentes. Nesse sentido, a exclusão está sendo concebida como um fenômeno também provocado por práticas pedagógicas autoritárias, uma vez que mudanças e transformações propiciadoras de avanços na aprendizagem e no desenvolvimento do aluno não são provocadas.

O fenômeno da exclusão pode ser ignorado ou compreendido como fatalidade por educadores. Por um lado, a invisibilização desse fenômeno explica-se pela dificuldade de os educadores reconhecerem a ineficácia do trabalho pedagógico por eles desenvolvido; por outro lado, o reconhecimento é admitido devido à atribuição da responsabilidade pela exclusão a fatores biológicos e sociais que fogem ao campo de atuação escolar. Esses posicionamentos ante a questão apresentada são caracterizados como subterfúgios dos educadores para a não-admissão da ineficácia da prática pedagógica vigente.

A subversão da exclusão, desejada e esperada por educadores, governantes e comunidade, pressupõe o reconhecimento da necessidade de transformação do exercício da docência, estando a responsabilidade pela 
virada almejada na dependência de esforços coletivos. Entre os esforços necessários, destaco o papel da universidade no tocante ao desenvolvimento de pesquisas colaborativas em escolas de séries iniciais, uma vez que, além de resolver problemas imediatos e desenvolver teorias, tais pesquisas também podem contribuir para a formação de professores reflexivos.

Objetivando mostrar a plena possibilidade de sucesso de alunos excluídos pela escola em que estudam, investigo, neste texto, as possíveis implicações da assunção da noção de gênero discursivo como instrumento semiótico de mediação para a aprendizagem e desenvolvimento de uma $\sigma^{a}$ série projeto, caracterizada como fracassada (Perrenoud, 2001) pela visão fatalista da comunidade escolar. No âmbito desta investigação, analiso o trabalho de mediação realizado durante uma atividade de reescrita de uma notícia por um aluno da turma mencionada.

A fundamentação teórica para a investigação realizada é oriunda basicamente de duas áreas de conhecimento: psicologia da educação e estudos da linguagem. Na primeira, são utilizados os trabalhos que tematizam a abordagem sociointeracionista da educação, como Baquero (2001), Oliveira (1997) e Vigotski (2001a, 2001b, 2003). Na segunda, são selecionados trabalhos que, com enfoque essencialmente teórico, discutem a função da linguagem na interação cotidiana e a concepção de gênero discursivo, como Bakhtin (2000, 2002) e Martin (1997), e, com enfoque aplicado ao ensino de língua materna, discutem o trabalho didático a partir da noção de gênero discursivo, como Schneuwly, Dolz e col. (2004).

No tocante à organização do trabalho, este texto está dividido em quatro partes. Na primeira, caracterizo a escola em que foi feita a intervenção pedagógica para a coleta do corpus de pesquisa, bem como os alunos e a professora participantes da pesquisa. $\mathrm{Na}$ segunda, faço uma revisão dos principais pressupostos teóricos vigotskianos pertinentes para os objetivos propostos na investigação. Na terceira, caracterizo os gêneros discursivos como instrumentos semióticos passíveis de contribuição para a aprendizagem e o desenvolvimento do indivíduo na escola. Na última parte, analiso as possíveis contribuições de duas atividades escolares para o desenvolvimento e a aprendizagem do sujeito, assim como a transcrição da interação entre um aluno e o pesquisador durante a realização de uma das atividades mencionadas.

\section{Caracterização da intervenção pedagógica e do corpus investigado}

O corpus utilizado na investigação proposta faz parte da pesquisa de doutorado que desenvolvi no campo dos estudos aplicados da linguagem. Na pesquisa, analisei como a professora participante da investigação inova a prática de ensino de língua portuguesa a partir da assunção das noções de texto e de gênero discursivo como objeto de ensino e unidade de análise, respectivamente, numa escola estadual no subúrbio da cidade de Campinas, estado de São Paulo. O trabalho pautado nessas noções demanda uma ressignificação das práticas de leitura, produção de texto e gramática, conforme orientam as diretrizes curriculares nacionais para o ensino fundamental II (Brasil, 1998). A unidade didática elaborada pela professora e pelo pesquisador tinha como temática o gênero rótulo, não pressupondo que esse tenha sido o único gênero discursivo contemplado, pois entrevistas, receitas, instruções de uso, notícias, entre outros gêneros, também foram trabalhados.

A professora participante da pesquisa passou por uma capacitação desenvolvida numa grande universidade estadual paulista e tais orientações curriculares foram o eixo teórico do conteúdo trabalhado no curso de formação continuada. Desenvolvido no segundo semestre de 2003, esse curso fez parte da primeira etapa de um projeto do governo do estado de São Paulo denominado Teia do Saber. Nessa primeira etapa do projeto, assumi a turma que a professora colaboradora freqüentou, portanto acredito que, sem vínculos oficiais, a intervenção realizada na escola foi uma extensão do curso mencionado. Em outras palavras, as orientações teórico-metodológicas desenvolvidas durante os dez encontros de oito horas que compuseram o curso foram postas em prática durante 
a intervenção realizada na escola em quase todo o primeiro semestre de 2004.

Os alunos da $6^{\text {a }}$ série fazem parte do projeto do governo do estado de Tocantins denominado Projeto $\mathrm{ABC}$ que, separando numa mesma turma os alunos da mesma série com graves problemas de aprendizagem, é proposto para recuperar a defasagem de aprendizagem. Utilizo a denominação excluídos para caracterizar os alunos da $6^{\mathrm{a}}$ série $\mathrm{E}$, justificando-se tal escolha pela posição ocupada por eles na organização social do espaço escolar. De forma estigmatizada, os alunos dessa turma são separados dos demais estudantes da instituição. Um registro, no diário de campo, da fala de uma mãe, na reunião de pais, evidencia tal estigma. O registro "Uma mãe diz que, na sala do filho, tem de tudo, é o ninho" traça com pontilhados fortemente delineados a divisão do espaço social. No cotidiano brasileiro, a expressão "ninho" é utilizada para caracterizar um lugar habitado ou freqüentado por pessoas de todo tipo, as quais, muitas vezes, são comparadas a cobras venenosas, daí a expressão análoga "ninho de cobra".

Os pressupostos teóricos referentes à organização do espaço social propostos por Bourdieu (2001, p. 27) são úteis para evidenciar a razão da escolha do rótulo atribuído aos educandos. Para o autor, todo espaço social se encontra dividido, o que é provocado pelo que denomina capital simbólico. ${ }^{1}$ Considerando as declarações explícitas e oficiais dos educadores atuantes na escola, nos termos de Bourdieu (idem, p. 149), o baixo capital cultural ou, mais especificamente, $c a-$ pital escolar proporciona a delineação do espaço na instituição. Faltam aos alunos dessa turma os saberes escolares, autênticas credenciais para transitar do lado oposto do espaço. Para corrigir um erro, que acredito ter sido produzido pela própria instituição, 22 alunos

1 Nas palavras do autor, "o capital simbólico é uma propriedade qualquer (de qualquer tipo de capital, físico, econômico, cultural, social), percebida pelos agentes sociais cujas categorias de percepção são tais que eles podem entendê-las (percebê-las) e reconhecê-las, atribuindo-lhes valor" (Bourdieu, 2001, p. 107). são separados numa minúscula classe para desfrutarem de um trabalho supervisionado "especial".

Para justificar o baixo rendimento desses alunos na escola, é comum os professores sobreporem a limitação dos saberes escolares a comportamentos e atitudes de familiares dos estudantes rechaçados pelas coordenadas sociais de boa conduta. As limitações dos saberes escolares apontadas pelos professores são morosidade para realizar atividades, problemas de grafia e incapacidade de produzir textos, ao passo que os comportamentos e atitudes apresentados como justificativas das limitações são problemas de alcoolismo, prostituição, espancamento e exploração de trabalho infantil.

Especificamente para este trabalho, é utilizada, como estratégia para coleta de dados de pesquisa, uma atividade proposta pela professora de língua portuguesa do ano letivo anterior ao que foi realizada a coleta do corpus, uma vez que as atividades desenvolvidas no momento anterior e durante a intervenção são comparadas nesta investigação. A atividade foi reproduzida do caderno volante da turma arquivado na escola, sendo essa prática ainda utilizada durante as aulas por professores e alunos para registrar as atividades propostas.

Diferentes versões de um texto do gênero notícia produzido por um aluno (GC) durante a intervenção realizada na escola e a transcrição de uma interação entre o pesquisador $(\mathrm{P})$ e o aluno produtor da notícia, durante a atividade de reescrita do texto desse gênero, também são utilizadas como corpus para a investigação realizada. A atividade de reescrita foi realizada no laboratório de informática da escola, portanto o computador foi utilizado como uma ferramenta auxiliar na atividade.

O texto do discente utilizado na análise foi selecionado devido ao registro da gravação da interação entre o pesquisador e o aluno. A gravação aconteceu de forma espontânea, pois o gravador para registrar a aula foi posicionado ao lado do computador em que o aluno estava reescrevendo o texto. Apenas durante a interação o pesquisador percebeu o fato, levando-o a tomar as devidas precauções para registrar todo o processo. 
O aluno envolvido na pesquisa estuda desde a $1^{\mathrm{a}}$ série na escola em que foi coletado o corpus e não possui repetência alguma no histórico escolar. Ele é caracterizado pelos professores como um dos melhores alunos da turma. No ano letivo anterior, também fez parte de uma $5^{\mathrm{a}}$ série do Projeto $\mathrm{ABC}$, turma em que foi proposta a atividade supramencionada que também foi selecionada como corpus para este trabalho. Nascido na cidade de Campinas, o aluno é o filho mais novo de um casal com quatro filhos.

\section{Processo vigotskiano de desenvolvimento e aprendizagem}

$\mathrm{O}$ aspecto de interesse da psicologia que distingue os humanos das demais espécies animais, segundo os postulados teóricos vigotskianos, são os denominados processos ou operações elementares e superiores. Os primeiros dispensam o planejamento, caracterizam-se por ações reflexas ou reações automatizadas, sendo comuns às espécies animais, ao passo que os segundos são identificadores da espécie humana, uma vez que são caracterizados pelo planejamento, controle e liberdade do indivíduo para agir em sociedade.

Esses processos superiores são complexificados ao longo da vida do homem por intermédio do uso de signos e instrumentos, os quais, em termos vigotskianos, são concebidos como elementos mediadores. Para essa linha teórica, os estímulos não motivam uma resposta direta, mas elementos mediadores emergem como mecanismos intermediários em situações que exigem resolução de problemas. Os processos superiores ou avançados, nas palavras de Baquero (2001, p. 90), são constituídos pelo "caráter crescentemente descontextualizado dos instrumentos de mediação envolvidos em sua formação e pelo domínio com maior grau de consciência e vontade das próprias operações intelectuais".

Os signos são compreendidos como elementos portadores de conteúdo semântico, daí a função de nomear ou classificar desempenhada por eles. Os ins- trumentos, por sua vez, são espécies de ferramentas que auxiliam na ação humana sobre o espaço social. Nas palavras de Oliveira (1997, p. 30), "os instrumentos são elementos externos ao indivíduo, voltados para fora dele; sua função é provocar mudanças nos objetos, controlar processos naturais". Os signos, segundo a autora, "são orientados para o próprio sujeito, para dentro do indivíduo; dirigem-se ao controle de ações psicológicas, seja do próprio indivíduo, seja de outras pessoas". Os signos são denominados instrumentos psicológicos por Vigotski (2001b), uma vez que auxiliam na organização e no planejamento do pensamento.

Caracterizada como um sistema de signos historicamente e culturalmente determinado, a escrita é um dos principais instrumentos de mediação na sociedade letrada. Na abordagem marxista proposta por Bakhtin (2002), no campo da filosofia da linguagem, a palavra escrita ou falada possui uma natureza ideológica, permitindo a indexação de valores e conflitos sociais na estrutura lingüística. Através do uso da língua nas interações sociais, o indivíduo age sobre o interlocutor, sofre transformações motivadas pela presença do outro e transforma a própria língua utilizada como elemento de mediação nas situações de comunicação. Em síntese, "aquilo que torna o signo ideológico vivo e dinâmico faz dele um instrumento de refração e de deformação do ser" (Bakhtin, 2002, p. 49).

A potencialidade para as operações avançadas com signos existe nos estágios precoces de desenvolvimento dos indivíduos (Vigotski, 2003, p. 61). As pessoas nascem com faculdades comportamentais biologicamente dadas e adquirem outras culturalmente, configurando a aprendizagem como um processo contínuo desencadeado por fatores exteriores à natureza biológica do homem. A ênfase na compreensão da aprendizagem como resultado do contato do homem com seus semelhantes num espaço construído sóciohistoricamente é um dos aspectos centrais de identificação da proposta teórica designada como sociointeracionismo.

As ações e retroações motivadas pelo uso de signos em atividades de comunicação remetem à função 
do professor na interação em sala de aula. A interação instaurada evidencia a relação construída entre o professor e os alunos, provocando algum efeito na aprendizagem e no desenvolvimento destes últimos, não significando que os professores saiam ilesos da situação. As estratégias de mediação, refletidas em atividades didáticas e na fala do professor, podem ser configuradas como desafios que se adiantam ao conhecimento possuído pelos alunos, desencadeando a aprendizagem. As interações entre os próprios alunos em sala de aula também são situações motivadoras da aprendizagem e do desenvolvimento.

Dado o fato de a interação entre atores sociais envolver troca de experiência e aprendizagem (Bakhtin, 2002), não podendo ocorrer desprovida de mediação, a proposição vigotskiana de trajetória independente entre o pensamento e a linguagem, nos primeiros meses de vida do indivíduo, parece problemática. Para o autor, no texto de Oliveira (1997, p. 45),

[...] num determinado momento do desenvolvimento filogenético, essas duas trajetórias se unem e o pensamento se torna verbal e a linguagem racional. A associação entre pensamento e linguagem é atribuída à necessidade de intercâmbio dos indivíduos durante o trabalho, atividade especificamente humana.

Antes do desenvolvimento do denominado pensamento verbal e da linguagem intelectual, o comportamento humano evidencia uma espécie de inteligência prática, pois, segundo Vigotski (2001b), assim como fazem os chimpanzés ao longo da vida, o homem utiliza instrumentos para resolver problemas sem auxílio da linguagem, caracterizando essa fase como pré-verbal do desenvolvimento do pensamento. Em contrapartida, a emissão de sons e a utilização de gestos e expressões faciais pela criança, nos primeiros meses de vida, assim como também acontece durante toda a vida dos chimpanzés, constitui um meio de contato psicológico com outros membros da sociedade, caracterizando esse uso da linguagem como pré-intelectual, no sentido de que ela não possui função de signo, o que não parece ser totalmente convincente, haja vista que o contato com outras pessoas atribui significado a sons, gestos ou expressões, estabelecendo negociações ou interações entre o infante e a pessoa mais experiente, assim como o manuseio de instrumentos pode ser motivado por algum significado, ou o próprio manuseio pode adquirir significado. Afinal, utilizando as próprias palavras de Vigotski (2003, p. 110), "aprendizagem e desenvolvimento estão interrelacionados desde o primeiro dia de vida da criança".

$\mathrm{Na}$ interação social, ocorrem os processos denominados intersubjetivos, responsáveis pela aprendizagem. Os adultos ou as pessoas mais experientes, utilizando-se de signos ou instrumentos, fazem a atividade de mediação responsável pela interiorização de conceitos ou práticas. Tal aprendizagem, iniciada na coletividade, tem continuidade na mente do indivíduo, configurando o processo chamado de intrasubjetivo. Em sala de aula, o trabalho de mediação do professor deveria funcionar dessa forma, pois, após exposições, conversas e discussões, espera-se que os alunos internalizem o conteúdo trabalhado, garantindo-lhes autonomia.

Para ilustrar esses processos, retomo a explanação sobre a transição das operações elementares para as superiores ou avançadas, propostas por Vigotski (2001b). De acordo com o autor, a exposição da criança a falas sociais, originárias de diálogos com atores mais experientes, possibilita o desenvolvimento da chamada fala egocêntrica, que corresponde a enunciados oralizados cuja função é orientar a ação executada pela criança. Ou seja, as ações são oralizadas à medida que são executadas. Num estágio mais avançado, essa fala egocêntrica é internalizada, daí o termo fala interior. Responsável pelo planejamento da ação e do controle do comportamento, a fala interior possibilita o envolvimento da criança em atividades complexas.

Nesta breve revisão dos fundamentos teóricos vigotskianos, destaco não apenas o processo de aprendizagem e desenvolvimento da linguagem no homem, mas também o fato de a linguagem exercer um papel sine qua non na aprendizagem e no desenvolvimento de qualquer habilidade constitutiva da atividade so- 
cial humana. Para Vigotski, a linguagem desempenha a função de comunicação e de generalização. A primeira é responsável pela interação entre os falantes nas diversas situações de comunicação, ao passo que a segunda é responsável pelas atividades de classificação e categorização (Baquero, 2001, p. 50; Oliveira, 1997, p. 42). No bojo dessas concepções, encontra-se a noção de linguagem como atividade ou forma de ação na sociedade.

A própria acepção vigotskiana de signo lingüístico exemplifica o dinamismo da linguagem, pois, além de ser utilizado como instrumento de mediação durante a comunicação, o signo sofre transformações, daí as noções de significado e sentido propostas na teoria. Ao discutir tais noções, Oliveira (idem, p. 50) afirma que o primeiro "consiste no núcleo relativamente estável de compreensão da palavra, compartilhado por todas as pessoas que a utilizam". O segundo, por sua vez, "refere-se ao significado da palavra para cada indivíduo, composto por relações que dizem respeito ao contexto de uso da palavra e às vivências afetivas do indivíduo". Este último é uma evidência da instabilidade constitutiva da linguagem, uma vez que os falantes transformam a língua durante o uso, dando-lhe a cada instante um novo sopro de vida, uma nova carga ideológica, conforme Bakhtin (2002).

Para o sociointeracionismo, a aprendizagem e o desenvolvimento não são processos totalmente independentes, nem podem ser concebidos como intrinsecamente dependentes, uma vez que se corre o risco de cair num velho problema pedagógico, o da disciplina formal, que condiciona o desenvolvimento da criança à aprendizagem dos conteúdos disciplinares. Apesar de afirmar que a aprendizagem não é desenvolvimento, Vigotski (2001a, 2003) afirma que este último processo sucede o primeiro. Nas palavras do autor, "a aprendizagem é um momento intrinsecamente necessário e universal para que se desenvolvam na criança características humanas não-naturais, mas formadas historicamente" (Vigotski, 2003, p. 115). Um outro argumento contrário ao problema da disciplina formal, podendo ser de grande proveito para o trabalho escolar, é o fato de que o "aprendizado das crianças começa muito antes de elas freqüentarem a escola". Ainda utilizando as palavras do autor, destaco que "qualquer situação de aprendizado com a qual a criança se defronta na escola tem sempre uma história prévia" (idem, p. 110), o que precisa ser considerado pelo professor no processo de ensino, daí a importância do constante diagnóstico para observar habilidades possuídas pelo aprendiz e para planejar novos conhecimentos a serem assimilados.

O trabalho escolar orientado por duas noções de níveis de desenvolvimento propostas por Vigotski (2001a, 2003) pode ser bastante proveitoso, pois eles permitem a otimização do desenvolvimento do discente. O primeiro é denominado nível de desenvolvimento real ou efetivo. Nomeia as funções que já amadureceram, que são produtos finais do desenvolvimento do indivíduo. O segundo é chamado de nível de desenvolvimento potencial. Nomeia as funções passíveis de serem exercidas pelos indivíduos com a ajuda de pessoas mais experientes. A autonomização do indivíduo para desempenhar as funções ainda não amadurecidas ocorre por via da imitação, que, na interpretação de Oliveira (1997, p. 63), “não é mera cópia de um modelo, mas reconstrução individual daquilo que é observado nos outros". A distância entre o nível de desenvolvimento real e o nível de desenvolvimento potencial do sujeito é denominada por Vigotski (2001a, p. 112; 2003, p. 112) área ou zona de desenvolvimento proximal - ZDP. O professor precisa atuar nessa área para que a aprendizagem e o desenvolvimento de fato ocorram.

Dado o interesse da investigação realizada neste texto e o uso de argumentos relacionados a fatores biológicos e sociais para justificar a inexistência de aprendizagem de alunos caracterizados como fracassados pela escola, destaco o risco em que incorrem os docentes de não realizarem um trabalho na área de desenvolvimento proximal do aprendiz, mas subjugarem o nível de desenvolvimento real do discente, o que resulta num percurso contrário ao que é proposto no trabalho diferencial. O próprio fato de separar os piores alunos numa mesma turma, configurando uma espécie de homogeneização, pode prejudicar a apren- 
dizagem, pois, juntos aos demais alunos, situações desafiadoras mais diversificadas surgiriam na interação, podendo impulsionar o desenvolvimento. Em situações desse tipo, a afirmação de Vigotski (2003, p. 117) de que "o bom aprendizado é somente aquele que se adianta ao desenvolvimento" precisa ser constantemente lembrada.

Apresentados os conceitos centrais da abordagem sociointeracionista e pensando nas possíveis contribuições do ensino de língua materna para o desenvolvimento do aluno, evitando a exclusão escolar, chamo a atenção para o trabalho de mediação realizado em sala de aula. Em aulas de língua portuguesa, as atividades escolares propostas deveriam servir como bons modelos do uso adequado da língua escrita ou falada em diferentes situações sociais da vida cotidiana.

\section{Gênero discursivo como objeto de ensino e instrumento semiótico}

Os Parâmetros Curriculares Nacionais ( $\mathrm{PCN})$ de Língua Portuguesa (Brasil, 1998), diretrizes curriculares vigentes para o ensino da língua materna no Brasil, orientam técnicos e professores para revisão e elaboração de propostas didáticas que possibilitem o uso da língua escrita e falada em diferentes situações sociais dentro e fora da escola. No documento, é proposta uma formação que possa ir além do que é identificado como modelo tradicional de alfabetização, compreendido por atividades simples e mecânicas com a escrita, características do espaço escolar. Nesse sentido, é orientada a proposição de atividades com a escrita verdadeira, ${ }^{2}$ a qual possibilita a inserção dos alunos em práticas sociais de uso da escrita enquanto tecnologia e sistema simbólico, configurando-se como práticas factuais de letramento (Kleiman, 1995, p. 19).

Em resposta à necessidade de inserção dos alunos em práticas de letramento, os PCN (Brasil, 1998,

2 Essa expressão é utilizada por Leite (2001, p. 25), ao falar de concepções de escrita que se opõem ao modelo tradicional de alfabetização. p. 20) apresentam o texto como unidade de análise e o gênero discursivo como objeto de ensino. A assunção dessas categorias é justificada pela adequação do enunciado produzido ao gênero, uma vez que, como afirma Bakhtin (2000, p. 301), todos os enunciados dispõem de uma forma padrão e relativamente estável de estruturação de um todo, os gêneros do discurso. Quaisquer enunciados, falados ou escritos, produzidos na cadeia da interação verbal, são textos que se moldam aos gêneros, os quais, por sua vez, são espécies de modelos semióticos construídos cooperativamente pelos usuários da língua nas atividades de interação. Neste trabalho, uma das teses defendidas é que os gêneros são instrumentos facilitadores dos denominados processos ou operações mentais superiores propostos nos postulados vigotskianos.

Os gêneros discursivos, segundo Bakhtin (idem, p. 280), são compostos por "unidade temática, estilo, construção composicional e funcionalidade", estando todos esses elementos intrinsecamente relacionados e determinados por enunciados passados e futuros. A unidade temática corresponde ao assunto ideologicamente marcado, abordado na materialidade lingüística; o estilo pode ser lingüístico ou individual, estando o primeiro relacionado às escolhas lingüísticas identificadoras do gênero, enquanto o segundo corresponde aos usos lingüísticos identificadores do produtor/autor. Diferentemente do estilo, atrelado ao nível microtextual do gênero, a construção composicional define a organização da macroestrutura textual do gênero, organização de parágrafos e partes. A funcionalidade designa a utilidade ou o objetivo proporcionado pela escolha do gênero discursivo.

O texto é uma estrutura lingüística gramaticalmente articulada que possui uma unidade significativa. A articulação gramatical dos elementos lingüísticos no texto é responsável pela coesão textual, também contribuindo para a construção do sentido produzido na interação entre a materialidade lingüística e o leitor, o qual aciona diversos conhecimentos adquiridos na história de vida, durante o momento da leitura. A coesão 
textual, atrelada à organização de informações no enunciado, corrobora a coerência textual, unidade de sentido expressa. A existência de textos está condicionada à incorporação de gêneros discursivos (Koch, 2002).

A apropriação de diferentes gêneros discursivos como habilidade de uso da língua falada e escrita pelo homem, em situações diversas de comunicação, está subjacente à proposta curricular para o letramento, o que é bastante coerente, haja vista que os gêneros são modelos de contextos culturais orientadores da ação do homem no espaço social (Martin, 1997). Esses modelos funcionam como signos, pois representam situações de produção textual resultantes de uma elaboração histórica constante que ocorre pelo uso da própria linguagem. A instabilidade constitutiva dos gêneros discursivos é um aspecto destacado, pois eles sofrem transformações para atender às necessidades de interação cada vez mais complexa da sociedade letrada.

Considerando a abordagem pedagógica para o letramento do aluno, os gêneros discursivos são concebidos como instrumentos semióticos (Schneuwly, Dolz \& col., 2004), pois podem ser utilizados como elementos de mediação entre o sujeito e a situação de comunicação. Adequando as produções textuais faladas e escritas a esses instrumentos semióticos, configuradores das situações de comunicação, o aprendiz pode tomar parte nas efetivas práticas de letramento. Nessa perspectiva, concordo com Baquero (2001, p. 38) ao afirmar que

[...] os instrumentos semióticos parecem estar orientados principalmente para o mundo social, para os outros. A linguagem, como exemplo de um dos instrumentos semióticos mais versáteis e desenvolvidos, reúne a potencialidade de poder ser dirigido e utilizado com funções e características diversas.

Esse novo encaminhamento dado às aulas de língua materna pode ser esclarecido por Schneuwly, Dolz e col. (2004, p. 75), pois consideram os gêneros discursivos "megainstrumentos que fornecem um suporte para a atividade, nas situações de comunicação, e uma referência para os aprendizes". Dada a natureza do espaço escolar, as atividades de ensino podem simplificar a essência da proposta do trabalho com gêneros, que, como foi ressaltado, é aproximar as atividades escolares das práticas efetivas de uso da tecnologia da escrita no cotidiano. A esse respeito, destaco três desdobramentos, mencionados pelos autores (idem, p. 76), que ocorrem no trabalho com gêneros na escola, uma vez que esses instrumentos semióticos, além de serem utilizados para comunicação, também são utilizados como objeto de ensino e aprendizagem: "desaparecimento da comunicação; escola como lugar da comunicação; negação da escola como lugar da comunicação”.

O primeiro desdobramento corresponde à prática em que são produzidos gêneros tipicamente escolares, como a narração e a dissertação, além do trabalho com os textos clássicos da literatura. Nessa prática, a noção de gênero é achatada e, de fato, o trabalho é realizado unicamente com o texto, sempre visando à avaliação das capacidades do aluno. O segundo desdobramento é caracterizado pela transformação da situação de comunicação na sala de aula num espaço de geração de gêneros. A produção desses instrumentos não é enfocada como objeto de ensino, mas procura-se criar necessidades de produção de gêneros para circular na escola. O terceiro desdobramento corresponde à prática em que os gêneros são trabalhados tais quais são encontrados fora da escola. Situações de circulação de gêneros na vida cotidiana são reproduzidas na escola, como se não houvesse desdobramento algum. As práticas subjacentes a esses diferentes desdobramentos não são excludentes, são complementares.

\section{Análise dos dados: subvertendo a exclusão}

Antes de analisar a atividade fundamentada na noção de gênero discursivo desenvolvida na $6^{a}$ série $\mathrm{E}$, chamo a atenção para as atividades desenvolvidas com a mesma turma de projeto no ano anterior. Seguindo a orientação da coordenação para o primeiro bimestre, os professores trabalharam os conteúdos 
disciplinares em torno do assunto tematizado numa reportagem do jornal da cidade, que noticiava a morte de uma anta por ter ingerido um saco plástico deixado no local por visitantes do bosque do município.

Reproduzo abaixo uma atividade representativa do trabalho desenvolvido pela professora de língua portuguesa com os alunos da turma em que foi realizada a intervenção. Na ocasião, eles estavam na $5^{\text {a }}$ série projeto:

Figura 1 - Atividade no caderno-piloto

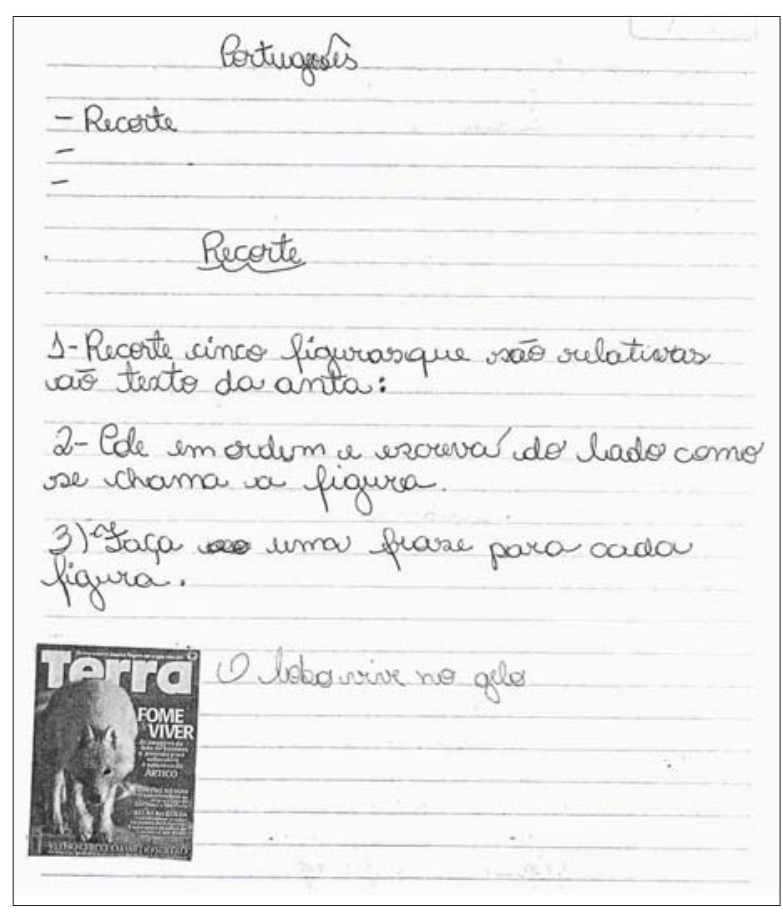

A observação da atividade permite caracterizála como autenticamente escolar, uma vez que a comunicação desaparece completamente numa situação de sala de aula em que as questões sejam propostas. A primeira questão está restrita a uma simples atividade de recorte e colagem, pois, se o objetivo for trabalhar compreensão textual, pouco acrescenta ao aluno. Em resposta à questão, foi colada a figura da capa de uma revista com um lobo do gelo. Tirando o fato de um animal estar presente na capa da revista, a figura pouco está relacionada ao bosque da reportagem, haja vista que o lobo do gelo não é característico de regiões tropicais, como o Brasil, e a figura não tematiza o inadequado comportamento humano praticado. A segunda questão parece ser bastante confusa, pois não está claro qual é ordem solicitada, nem tampouco quais os nomes das figuras. Na figura colada pelo aluno, por exemplo, não há identificação, restando a dúvida se o aluno teria de nomear ou se teria de encontrar figuras com títulos. A terceira questão, que, de fato, poderia levar o aluno a produzir algo, está limitada à produção de frases sem funcionalidade alguma. Dificilmente se afirma $O$ lobo vive no gelo fora de um contexto cultural de comunicação específico.

Observada a primeira atividade, resta perguntar em que essa atividade poderia contribuir para a aprendizagem e o desenvolvimento dos alunos do denominado Projeto ABC. A atividade estaria realmente proporcionando uma aprendizagem que se adiantasse ao desenvolvimento do aluno? Como colaborar para a subversão da exclusão com tal atividade? Nenhuma das questões propostas como exercício possibilita um trabalho orientado pela noção de gênero discursivo, não há situação de comunicação como modelo a ser imitado pelos alunos, afinal, desconsiderando o texto sobre a anta tomado como ponto de partida para o exercício, o trabalho limita-se ao nível da frase.

É difícil admitir, mas a atividade reproduzida pode ter sido bastante útil para manter os alunos ocupados e gastar todo o tempo da aula, ainda que os estudantes se aborreçam com a falta de propósito do exercício. Em contrapartida, temo que atividades desse tipo sejam a última carta tirada da manga de professores inconformados por não poderem ensinar gramática, conteúdo disciplinar que lhes proporcionava segurança e dava razão às aulas de língua portuguesa. Nesse sentido, reitero a importância do diálogo entre as escolas e as universidades para subverter a exclusão provocada.

Analisada uma atividade representativa do trabalho realizado na turma de projeto antes da intervenção feita, investigo as possíveis contribuições das atividades orientadas pela noção de gênero do discurso para a aprendizagem e o desenvolvimento dos discentes. O texto do gênero notícia foi produzido por GC para ser publicado no jornal intitulado Jornal $6^{a}$ 
$E$, que foi criado durante a intervenção pedagógica realizada. Dito isso, a escola passou a ser o lugar da comunicação, pois foram criadas necessidades de escrita, levando os alunos a produzirem textos de diferentes gêneros para circularem na instituição e na família. Inserindo os alunos nessas práticas, procurou-se dar-lhes maior autonomia para usar a língua escrita e falada em situações específicas.

Antes da solicitação da produção da notícia, foram desenvolvidas diversas atividades de interpretação de diferentes textos de rótulos, dando ênfase à funcionalidade das informações contidas no gênero. Uma entrevista sobre o hábito de leitura de rótulos, elaborada pelos alunos e realizada com os pais, foi uma outra atividade que forneceu informações para os alunos produzirem a notícia. Após realizarem a entrevista, as respostas foram analisadas em sala de aula e produzidos gráficos com a cooperação da professora de matemática. No momento anterior à produção das notícias, foi realizada uma atividade de leitura com uma notícia sobre rótulos retirada do site do Jornal Nacional, da Rede Globo, servindo como modelo para o texto a ser escrito:

\section{Brasileiros não entendem informações das embalagens de alimentos ${ }^{3}$}

Uma pesquisa divulgada hoje concluiu que a maioria dos consumidores tem dificuldades para entender informações dos rótulos das embalagens de alimentos. Informações que agora serão obrigatórias também no comércio de frutas e legumes, entre outros produtos.

Um fiscal adverte o motorista de um caminhão: as uvas que ele transporta não têm identificação de origem, nem data de embalagem como exige a Agência Nacional de Vigilância Sanitária.

A central de abastecimento não tem poder para reter a carga. Mas o comerciante que comprou as frutas será in-

3 Disponível em: <http://jornalnacional.globo.com.site.jsp>. Acesso em: 25 nov. 2003. formado da irregularidade e em março do ano que vem, todos os alimentos deverão ter rótulo.

"O rótulo está dizendo para o consumidor: olha, consumidor, esse produto saiu da roça tal, de tal local, e a origem é essa. Portanto você pode consumir com garantia”, explica o assessor da Ceagesp, Euclides Amorim.

Os alimentos in natura são os últimos a entrar para a era da rotulagem. Ainda existem falhas, mas nunca no Brasil houve tanta informação nas embalagens de tudo que está à venda. $\mathrm{O}$ consumidor ainda está descobrindo a importância disso.

"Eu tenho colesterol, então eu tenho que ver o ingrediente que eu estou usando", diz uma senhora.

Em uma pesquisa feita em São Paulo pelo Instituto Brasileiro de Educação para o Consumo de Alimentos, $61 \%$ dos entrevistados disseram que lêem rótulos. Mas apenas $29 \%$ comparam e decidem a compra a partir do que está escrito.

"Eu diria que existe uma deficiência não por falta de informação no rótulo, mas por essa lacuna que existe entre a informação que está no rótulo e o entendimento do consumidor", explica Patrícia Fukuma, do Instituto Brasileiro de Educação para o Consumo de Alimentos.

Sempre é possível melhorar o texto, as letras. O consumidor só não quer mais é ficar no escuro, sem as informações no rótulo.

A primeira versão elaborada por GC está reproduzida adiante. Saliento que, para correção da primeira versão, a professora e o pesquisador procuraram fazer um bilhete com orientações para revisão de aspectos macrotextuais, compreendendo título e distribuição de informações em parágrafos. No entanto, por motivo não registrado, não foi produzido bilhete para o texto desse aluno, mas as orientações foram dadas durante a reescrita do texto no computador, momento em que, como é passível de observação adiante, além de realizar correções propostas por $\mathrm{P}, \mathrm{o}$ aluno realizou reformulações espontâneas. Na figura 2 , apresento a primeira versão da notícia produzida.

A notícia reproduzida possui alguns problemas na macro e microestrutura textual, os quais foram solucionados por diferentes mediações. Ressalto que 
muitos dos problemas só emergiram devido ao desembaraço de GC para escrever, haja vista que esse foi o texto mais longo da turma. Além da mediação realizada pela professora participante e por mim como pesquisador, o computador desempenhou uma importante função enquanto instrumento mediador para resolução de problemas na macro e microestrutura da notícia, com destaque para a primeira. Como foi perceptível na ocasião, o uso dessa máquina motiva os alunos a realizar as atividades propostas.

Figura $2-1^{\text {a }}$ Versão ${ }^{4}$

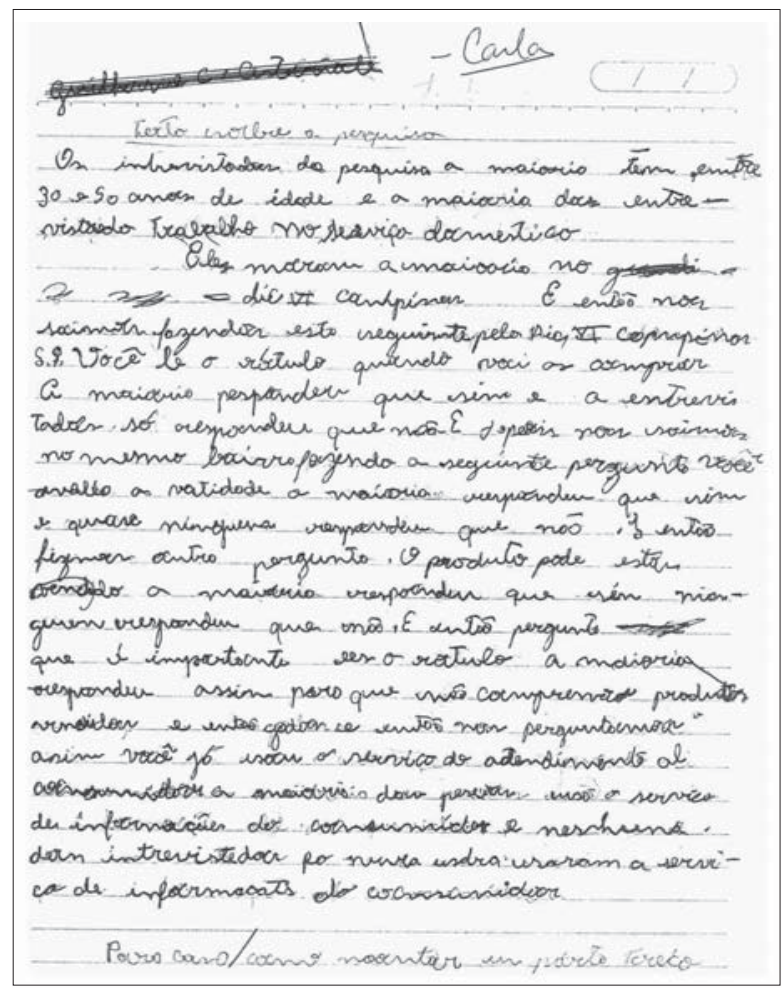

4 Os entrevistados da pesquisa a maioria tem entre 30 e 50 anos de idade e a maioria dos entrevistado trabalha no serviço domestico. Eles moram a maioria no dic VI Campinas E então nos saimos fazendo esta seguinte pelo Dic VI Campinas S. P. Você lê o rótulo quando vai as compras. A maioria respondeu que sim e a entrevistados só respondeu que não. E depois nos saimos no mesmo bairro fazendo a seguinte pergunta você avalia a validade a maioria respondeu que sim e quase ninguém respondeu que não. E então fizemos outra pergunta. O produto pode estar vencido a maioria respondeu que sim ninguém respondeu que não. E então pergunto
O problema da paragrafação foi solucionado pelo próprio aluno, haja vista que a primeira versão possui um parágrafo bastante curto que não caracteriza suficientemente os entrevistados da pesquisa, ao passo que o parágrafo seguinte apresenta as perguntas e respostas da entrevista realizada sem uma organização mínima. Acredito que a visualização do texto na tela do computador tenha permitido a autonomia do aprendiz para solucionar tais questões. A observação da versão final da notícia, reproduzida adiante, facilita a percepção das modificações. O primeiro parágrafo foi reorganizado e o segundo foi dividido em vários parágrafos, facilitando a leitura do texto publicado posteriormente no Jornal $6^{a} E$. Eis a versão final da notícia:

Figura 3 - Versão definitiva

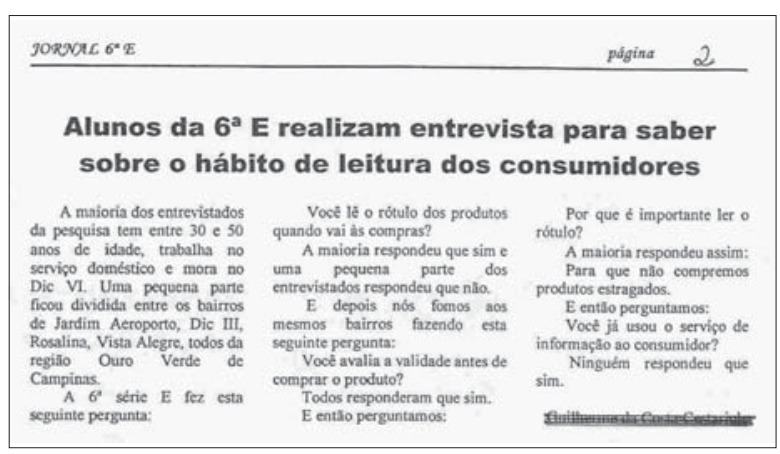

Acréscimo e supressão de passagens textuais também foram realizadas com o uso do computador enquanto instrumento de mediação. No primeiro parágrafo da versão definitiva, por exemplo, o aluno acrescentou uma informação sobre os demais bairros onde reside a minoria dos entrevistados ("Uma pequena parte ficou dividida entre os bairros de Jardim

que é importante ler o rótulo a maioria respondeu assim para que não comprasse produtos vencidos e então [incompreensível] e então nos perguntamos assim você já usou os serviço de atendimento al consumidor a maioria das pessoas usa o serviço de informações do consumidor e nenhuma dos entrevistados [incompreensíve1] usaram o serviço de informações do consumidor.

Para casa / como montar um porta-treco. 
Aeroporto, Dic III, Rosalina, Vista Alegre, todos da região Ouro Verde de Campinas"). Uma supressão realizada pelo discente corresponde às últimas pergunta e resposta explicitadas no final da segunda coluna da notícia no jornal ("Você avalia a validade antes de comprar o produto? Todos responderam que sim"). Na décima linha da primeira versão, estava escrito: "você avalia a validade a maioria respondeu que sim e quase ninguém respondeu que não. E então fizemos outra pergunta. O produto pode estar vencido a maioria respondeu que sim ninguém respondeu que não". Observa-se que, além de suprimir parte do texto, o aluno complementa a pergunta com a expressão "antes de comprar o produto".

O título posto na versão final da notícia ("Alunos da $6^{\mathrm{a}} \mathrm{E}$ realizam entrevista para saber sobre o hábito de leitura dos consumidores") foi produzido pela professora participante no momento da edição do jornal. Durante a reescrita, o aluno foi chamado a atenção sobre o título atribuído ao texto ("Texto sobre a pesquisa”), porém não conseguiu modificá-lo, o que é justificado pela falta de orientação específica para o propósito. Na realidade, o título da versão final prepara o leitor para ler a notícia, do contrário, ficaria a leitura bastante prejudicada sem o título atribuído.

Analisados os aspectos gerais referentes ao trabalho de mediação realizado, passo a investigar a interação entre $\mathrm{P}$ e GC referente à correção de aspectos da microestrutura textual do gênero. Acontecendo através do uso da língua enquanto instrumento de mediação, a interação objetiva modelar a notícia como instrumento semiótico para utilização pelos alunos em futuras situações de comunicação. Essa atividade de mediação ocorre por meio do que é denominado atividades epilingüísticas, nos estudos da linguagem. Essas atividades são compreendidas como "práticas que operam sobre a própria linguagem, compara as expressões, transforma-as, experimenta novos modos de construção canônicos ou não, brinca com a linguagem, investe as formas lingüísticas de novos significados" (Franchi, 1987, p. 41). Ressalto que as diretrizes curriculares vigentes orientam que o ensino de gramática tradicional seja reconfigurado pelas ativi- dades epilingüísticas, as quais podem contribuir para a aprendizagem e o desenvolvimento do aluno (Brasil, 1998; Silva, 2003).

O uso excessivo da expressão nominal a maioria, a inadequação do uso do conectivo $e$ e a escolha de uma expressão nominal adequada para o gênero notícia são os conteúdos lingüísticos enfocados em três momentos da interação analisados adiante. ${ }^{5}$ Apresento a seguir o primeiro momento da interação, quando $\mathrm{P}$ chama a atenção de GC para o uso excessivo da expressão a maioria.

$1^{\circ}$ Momento

1. CG: É:: e a maioria dos entrevistados trabalham no serviço doméstico ... ((lendo))

2. P: Uhm, presta atenção aqui ó, os entrevistados da pesquisa, a maioria tem trinta, tem entre trinta e cinqüenta anos de idade, a maioria dos entrevistados, não seria melhor a maioria dos entrevistados, né, cê coloca a maioria pra aqui, né. A maioria dos entrevistados da pesquisa tem entre trinta e cinqüenta anos ... não seria melhor?

3. GC: (Só é diminuir aqui) ...

4. P: Lê como está escrito.

5. GC: Os entrevistados da pesquisa e a maioria tem entre trinta e cinqüenta anos de idade, tinha que cortar aqui ó.

6. P: Onde?

7. GC: Os entrevistados da pesquisa ...

8. P: Não, coloca a maioria pra aqui para frente $\ldots a$ maioria dos entrevistados da pesquisa tem ... está entendendo?

9. GC: Como eu coloco?

\footnotetext{
5 Convenções de transcrição:

Itálico: $\quad$ passagem lida do texto do aluno;

MAIÚSCULA: ênfase na fala;

l.../ passagem da transcrição omitida;

(( )) comentário do analista;

( ) reconstituição da fala pelo analista;

-.. pausa;

: $\quad$ prolongamento da fala
} 
10.P: Tira essa maioria daqui, e bota aqui, seleciona, aí recorta aqui ... aí bota aqui pra frente e cola aqui ó, colar, colar ... a maioria .... /.../

11. GC: (Esse traço está dizendo que não tá certo) ...

12.P: Mas aí é porque você não pôs o ponto ainda ... tem esse aqui que está sublinhado verdinho, não é vermelho, está vendo, vermelho é quando está errado, verde é porque você deu um espaço a mais ... então, $a$ maioria dos entrevistados da pesquisa tem entre trinta e cinqüenta anos de idade e a maioria dos entrevistados ((D interrompe)) ... escreve o resto lá ... vai corrigindo se for necessário ...

13. GC: Professor, como faz aquilo lá, a professora ensinou colocar aqui no meio da palavra e apertar com a esquerda? ((pergunta a P novamente))

14. P: O quê? Pera aí ... Colocar o quê?

15. GC: Assim ó, aqui trabalham aí (tá de risquinho) verde, daí eu coloco, daí eu coloco lá no meio da palavra e fica isso daqui, era pra tá um monte de coisa ... ((GC posiciona o cursor do mouse em cima da palavra sublinhada))

16. P: Ah, sim, sim ... é porque trabalhão existe, mas ele está marcando aí que tem um problema de gramática aqui, não é a maioria dos entrevistados trabalhão, com ão ...

17. GC: Trabalham::: ...

18. P: Como é que se escreve?

19. GC: Eles trabalham ...

20.P: Ahm, como é que se escreve isso?

21. GC: $\operatorname{Com} M$ ?

22. P: É com $M$... agora lê como é que está ...

23. GC: Trabalham ... a maioria dos entrevistados trabalham ...

24. P: Lê do início, sim, a maioria dos entrevistados trabalham ...

25. GC: A maioria dos entrevistados da pesquisa tem entre trinta e cinqüenta anos de idade e a maioria dos entrevistados trabalham ...

26.P: Ó, vê quantos repetiu aqui, A maioria dos entrevistados da pesquisa tem entre trinta e cinqüenta anos de idade e a maioria dos entrevistados trabalham ...

27. GC: É, mas não deu para escrever de outro jeito ...

28. P: Como é que a gente pode melhorar? Para não repetir? 29. GC: ((pensa um pouco)) E trabalham ...

30.P: Ahm, exatamente ...
No intuito de que GC perceba os problemas textuais e adquira autonomia para evitar posteriores inadequações lingüísticas, algumas estratégias utilizadas no processo intersubjetivo podem ser observadas. Exercendo a função de detentor do conhecimento especializado, $\mathrm{P}$ solicita que o aluno preste atenção em passagens específicas e oferece outras alternativas, como na fala 2 (... "presta atenção aqui...", ... "não seria melhor...”). Outra estratégia utilizada na mediação é a solicitação da leitura da passagem textual em que há uma inadequação lingüística, como nas falas 4 ("Lê como está escrito") e 24 ("Lê do início..."). Em algumas ocasiões, P identifica o problema para GC e pergunta ao aluno como poderia ser solucionado o problema, como é perceptível nas falas 26 ("Ó, vê quantos repetiu aqui, A maioria dos entrevistados da pesquisa tem entre trinta e cinqüenta anos de idade e a maioria dos entrevistados trabalham...") e 28 ("Como é que a gente pode melhorar? Para não repetir?"). Destaco, nessa última estratégia, o fato de GC afirmar que não pôde escrever diferente, linha 27 ("É, mas não deu para escrever de outro jeito...”), e, após a pergunta realizada por $\mathrm{P}$, o aluno apresentar uma alternativa, linha 29 (“ $E$ trabalham...”), que soluciona a repetição desnecessária da expressão a maioria. Acredito que a apresentação da resposta pelo aluno seja um indício de autonomia, pois ele aparenta começar a compreender como funciona a construção lingüística.

Ainda analisando o primeiro momento da interação, chamo a atenção para a interferência do computador como instrumento de mediação na interação entre o pesquisador e o aluno, pois, como pode ser observado da fala 11 à fala 21 , o sublinhado na cor verde aparece na tela do computador sob a passagem textual circunscrita à palavra trabalhão, levando o aluno a procurar uma solução para o provável erro destacado. Na tentativa de justificar o questionamento do aluno, motivado pelo comando do computador, na fala 15 (“Assim ó, aqui trabalham aí (tá de risquinho) verde, daí eu coloco, daí eu coloco lá no meio da palavra e fica isso daqui, era pra tá um monte de coisa"), o pesquisador dá uma resposta não completamente correta na fala 16 (“Ah, sim, sim... é porque 
trabalhão existe, mas ele está marcando aí que tem um problema de gramática aqui, não é a maioria dos entrevistados trabalhão, com ão"), pois a forma verbal existente é trabalharão, diferentemente da utilizada por GC.

Continuando a analisar a interação entre P e GC, apresento adiante o segundo momento dessa situação de aprendizagem, que representa de forma significativa o denominado processo intersubjetivo a que fez referência Vigotski (2001b). Nesse momento da interação, destaco as referências feitas pelo pesquisador a conteúdos trabalhados em outros momentos, que podem auxiliar o aprendiz a substituir o conectivo $e$ utilizado em excesso. Eis a segunda parte da interação:

\section{$2^{\circ}$ Momento}

1. P: Antes disso, vamos ver aqui, a maioria dos entrevistados da pesquisa tem entre trinta e quinze anos de idade ...

2. GC: Cinqüenta ...

3. P: Cinqüenta, e trabalha no serviço doméstico e eles moram no Dic ... Pra não repetir $E, E \ldots$

4. GC: Dic III ...

5. P: Como que a gente faz?

6. GC: Pra não repetir?

7. P: Pra não repetir $E, E$, lembra que você disse que queria aqui colocar um ponto antes do eles?

8. GC: Ahm ...

9. P: Lembra?

10. GC: Ahm ...

11.P: Quer dizer que pode corrigir aqui esse $E, E$ trabalham, a maioria tem entre trinta e cinqüenta anos de idade e trabalha no serviço doméstico ... tira o $E \mathrm{e}$ coloca o quê?

12. GC: Coloca ... idade ...

13.P: Quando a gente, lembra aquele exercício que a gente fez da pontuação? Quando vai citar várias coisas ...

14. GC: Quando vai citar, dois pontos ...

15.P: Quando vai citar, dois pontos, mas quando a gente está separando vários elementos que foram citados?

16. GC: Ponto e vírgula ...

17.P: Ponto e vírgula é no caso daquelas instruções, né? 18.GC: É ...

19.P: E dentro da instrução, numa frase?

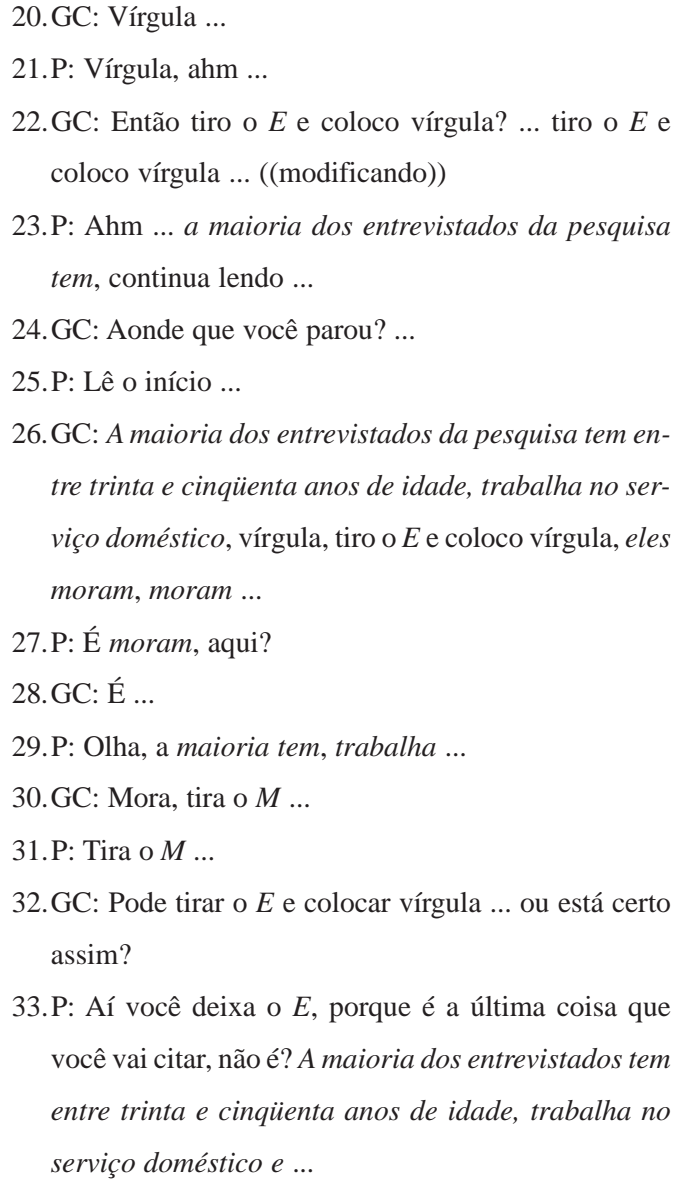

33. P: Aí você deixa o $E$, porque é a última coisa que você vai citar, não é? A maioria dos entrevistados tem entre trinta e cinqüenta anos de idade, trabalha no serviço doméstico e ...

As estratégias utilizadas para levar o aluno a solucionar o excesso do conector $e$ são semelhantes às mencionadas na análise do primeiro momento da interação, como se pode observar na linha 11 ("Quer dizer que pode corrigir aqui esse $E$, E trabalham, $a$ maioria tem entre trinta e cinqüenta anos de idade $e$ trabalha no serviço doméstico... tira o $E$ e coloca o quê?"), quando P lê a passagem a ser reescrita e insiste em fazer pergunta a GC. Motivado pelo pesquisador, o acionamento do conhecimento interiorizado pelo aluno é algo a ser destacado nesse segundo momento da interação, pois o saber acionado possibilita a correção do problema lingüístico.

As perguntas que retomam os usos de sinais de pontuação estudados anteriormente a partir do gênero instrução de uso pelos alunos caracterizam a interação como verdadeiras atividades epilingüísticas. As questões levantadas por $\mathrm{P}$, como é perceptível na fala 13 ("Quando a gente, lembra aquele exercício que a gente 
fez da pontuação? Quando vai citar várias coisas ...”), parecem não ser suficientes para possibilitar que GC chegue a uma resposta correta, pois o aluno aciona sinais de pontuação não adequados para substituir o conectivo, como se pode observar nas falas 14 ("Quando vai citar, dois pontos...") e 16 ("Ponto e vírgula..."). Apenas na terceira tentativa, falas 19 a 22 ("P: E dentro da instrução, numa frase? / GC: Vírgula ... / P: Vírgula, ahm ... / GC: Então tiro o $E$ e coloco vírgula?... tiro o $E$ e coloco vírgula..."), o aprendiz encontra a solução para o uso excessivo do conectivo.

Ainda no tocante ao segundo momento da interação, destaco as falas 26 ("A maioria dos entrevistados da pesquisa tem entre trinta e cinqüenta anos de idade, trabalha no serviço doméstico, vírgula, tiro o E e coloco vírgula, eles moram, moram...") e 32 de GC ("Pode tirar o $E$ e colocar vírgula ... ou está certo assim?"), pois, generalizando a orientação para o uso da vírgula, o aluno iria empregá-la na única situação em que o conector $e$ permaneceria, última oração coordenada. A generalização do emprego do conector é impedida pela mediação do pesquisador, podendo ser observada na fala 33 ("Aí você deixa o $E$, porque é a última coisa que você vai citar, não é? A maioria dos entrevistados tem entre trinta e cinqüenta anos de idade, trabalha no serviço doméstico e ...”).

Finalmente, no tocante ao terceiro momento da interação entre GC e P, observo em seguida as reflexões realizadas sobre a escolha da pessoa gramatical adequada para o gênero notícia. GC tenta aparecer no texto como autor, enquanto $P$ procura convencer o aluno a deixar o texto mais impessoal devido ao gênero notícia e reconhecer a pesquisa realizada com os pais como um trabalho coletivo, ainda que, na versão final, a impessoalidade só apareça onde o $\mathrm{P}$ fez a intervenção, permanecendo os demais verbos flexionados na primeira pessoa do plural, que, para GC, representa ele próprio. Eis a terceira parte da intervenção:

\section{$3^{\circ}$ Momento}

1. P: /.../ Então, até aí, está certo ... E então, fizemos essas seguintes perguntas ... é, fizemos quem, você tem que dizer quem ... quem foi que fez ...
2. GC: Como assim? E então

3. P: Você pôs e então fizemos essas seguintes perguntas ...

4. GC: Eu tenho que colocar meu nome?

5. P: Fizemos, quem foi que fez?

6. GC: Eu.

7. P: Só você?

8. GC: Eu fiz essas perguntas.

9. P: Como assim?

10. GC: Fizemos ...

11.P: Não são as entrevistas?

12. GC: Ah, não, fizemos pode ... só eu que fiz, não pode colocar no plural, né?

13.P: Não, pode ser, quem foi que fez? Foi você e os alunos, outros também?

14.GC: Não, essas perguntas aqui fui eu que fiz ... daí os outros alunos proporam outras, daí todo mundo criaram as mesmas perguntas ...

15.P: Então, mas isso que você está comentando agora não é algo que foi feito por todos, não? O resultado da pesquisa? Foi a turma toda que fez, não foi? Então, você vai colocar como? Quem foi que fez?

16.GC: A $6^{a}$ série $E$...

17.P: Então, $a \sigma^{a}$ série $E$, como é que fica isso?

18.GC: E então a $\sigma^{a}$ série $E$...

19. P: Pode pôr direto, sem o então, e então ...A $\sigma^{a}$ série $E$...

20. GC: $A 6^{a}$ série $E$... como é que coloca aquele negocinho?

21.P: O azinho pequeno?

22. GC: É.

23.P: É assim, ponto, aí ele muda, está vendo? ((digita para o GC)) ...a $\sigma^{a}$, coloca ...

24.D: Depois, você dá uma olhadinha?

25.P: Tá.

26.GB: Como faço o $E$ ?

27.P: $A \sigma^{a} E$... bota um $E$ maiúsculo ... É melhor série, não é? Isso aí não é uma pequena notícia que vai colocar no jornal? É melhor a $\sigma^{a}$ série E, bota aí série ... 28.GB: Vai ter que apagar aqui ...

29. P: Não, vai deixar o $E$ maiúsculo, aí ... não é $\sigma^{a}$ série $E$ ? 30.GB: Série E, $\sigma^{a}$ série $E$...

31.P: Então, já deixa o E aí, coloca só o série ...

32. GB: $A \sigma^{a}$ série $E$... ((digitando)) Série tem acento no $E$ ? 33. P: SÉrie ... A $\sigma^{a}$ série $E$, como é que fica agora? Fizemos? 34. GC: Não, a $\sigma^{a}$ série $E$ fez essas seguintes perguntas ... 
As perguntas continuam aparecendo como a principal estratégia no trabalho de mediação do pesquisador. Diversas perguntas, como a encontrada na fala 5 (“Fizemos, quem foi que fez?”), foram necessárias para que GC percebesse a pesquisa realizada como produto do trabalho coletivo. Essa dificuldade para reconhecer o trabalho coletivo torna-se mais evidente na fala 12 ("Ah, não, fizemos pode ... só eu que fiz, não pode colocar no plural, né?"), quando o aluno faz uma reflexão sobre o uso verbal na língua portuguesa bastante coerente.

Utilizando a apresentação da palavra série como alternativa para adequar a escrita de GC ao propósito da produção, fala 27 (“ $A \sigma^{a} E$... bota um $E$ maiúsculo... É melhor série, não é? Isso aí não é uma pequena notícia que vai colocar no jornal? É melhor a $\sigma^{a}$ série $E$, bota aí série ...”), P chama a atenção do aluno para realizar escolhas lingüísticas apropriadas ao gênero notícia, evidenciando uma atividade em que o texto é analisado considerando a funcionalidade da escrita. A pergunta final realizada por $\mathrm{P}$, na linha 33 ("Série... A $6^{a}$ série E, como é que fica agora? Fizemos?"), seguida pela resposta correta de GC, na linha 34 ("Não, a $6^{a}$ série Efez essas seguintes perguntas ..."), mostra que o aluno acompanha perfeitamente a reflexão mediada pelo pesquisador.

Diferentemente da primeira atividade analisada neste texto, proposta por uma professora de português para os alunos na $5^{a}$ série projeto, a atividade de produção textual realizada durante a intervenção parece ter um objetivo claro. Os momentos de escrita, visando a uma possível publicação no jornal da turma, devolvem à escrita a função que perdera nas aulas de língua materna, uma vez que as produções textuais reencontram os leitores. A atividade de reescrita instaura o verdadeiro diálogo entre alunos e professores, pois os enunciados encontram interlocutores atentos.

A produção da notícia certamente possibilitou situações de aprendizagem e desenvolvimento, pois a atividade criou situações desafiadoras para o aluno, sem subestimar o conhecimento por ele possuído. As observações realizadas pelo pesquisador parecem levar o aluno a realizar esforços na denominada zona de desenvolvimento proximal, uma vez que são realizadas procuras de novas versões lingüísticas, as quais são encontradas durante a interação. $\mathrm{O}$ gênero notícia pôde ser observado como "megainstrumento" (Schneuwly, Dolz \& col., 2004), pois, além de ter possibilitado o trabalho de leitura, produção e análise lingüística, foi apresentado como instrumento semiótico de referência para as práticas de uso da escrita no mundo fora da escola.

\section{Considerações finais}

A investigação realizada neste trabalho mostrou que a exclusão dos alunos da $6^{a}$ série $E$ pode ser subvertida, e que um forte suporte teórico é necessário para preparar atividades que possibilitem a aprendizagem e o desenvolvimento dos alunos. Os discentes não são fracassados, como afirmam os educadores da instituição, mas, na realidade, o fracasso pode ser atribuído à própria escola. Dado o exposto, as atividades nas aulas de língua materna deveriam servir de modelo para o bom desempenho dos discentes em situações de comunicação espontânea na sociedade, uma vez que, quando a funcionalidade dessas atividades está restrita à dinâmica da instituição escolar, os alunos podem realmente fracassar na vida.

As atividades interativas parecem ser bastante importantes para a aprendizagem e o desenvolvimento do discente, pois, dialogando com professores e amigos de turma, saberes possuídos são acionados, enquanto saberes novos são internalizados. Como mostram os diferentes momentos da interação analisada, o professor pode utilizar diferentes estratégias para solucionar situações problemas com os alunos, como propor perguntas e soluções alternativas ou insistir na leitura de passagens textuais inadequadas para que o aluno perceba a inadequação linguiística.

Acredito que o professor poderia refletir mais sobre a própria prática docente, evitando justificar o baixo aprendizado do aluno com adversidades por eles enfrentadas fora dos muros escolares. A escola deveria instrumentalizar os alunos para se inserirem nas práticas sociais de uso da língua falada e escrita, pois, 
assim fazendo, as redomas erigidas estarão demolidas, restando-lhes uma caminhada desafiadora em direção ao horizonte.

\section{Referências bibliográficas}

BAKHTIN, Mikhail. Estética da criação verbal. 3. ed. São Paulo: Martins Fontes, 2000.

Marxismo e filosofia da linguagem. 10. ed. São Paulo: Hucitec; Annablume, 2002.

BAQUERO, Ricardo. Vygotsky e aprendizagem escolar. Porto Alegre: Artmed, 2001.

BOURDIEU, Pierre. Razões práticas: sobre a teoria da ação. Campinas: Papirus, 2001.

BRASIL, Ministério da Educação. Parâmetros Curriculares Nacionais. Língua portuguesa: Ensino Fundamental II. Brasília: MEC, 1998. FRANCHI, Carlos. Criatividade e gramática. Trabalhos em lingüística aplicada, Campinas,UNICAMP/Instituto de Estudos da Linguagem, n. 9, p. 5-45, 1987.

KLEIMAN, Angela. Modelos de letramento e as práticas de alfabetização na escola. In: KLEIMAN, Angela (Org.). Os significados do letramento: uma perspectiva sobre a prática social da escrita. Campinas: Mercado de Letras, 1995. p. 15-61.

KOCH, Ingedore G. V. Desvendando os segredos do texto. São Paulo: Cortez, 2002.

LEITE, Sérgio A. da S. Notas sobre o processo de alfabetização escolar. In: LEITE, Sérgio A. da S. (Org.). Alfabetização $e$ letramento: contribuições para as práticas pedagógicas. Campinas: Komedi; Arte Escrita, 2001. p. 21-45.

MARTIN, James. Analysing genre: functional parameters. In: CHRISTIE, Frances; MARTIN, James (Orgs.). Genre and Institutions: social processes in the workplace and school. London/ Washington: Cassel, 1997. p. 3-39.

OLIVEIRA, Marta K. de. Vygotsky: aprendizagem e desenvolvimento: um processo sócio-histórico. São Paulo: Scipione, 1997.

PERRENOUD, Philippe. A pedagogia na escola das diferenças: fragmentos de uma sociologia do fracasso. Porto Alegre: Artmed, 2001. SCHNEUWLY, Bernard; DOLZ, Joaquim e colaboradores. Gêneros orais e escritos na escola. Campinas: Mercado de Letras, 2004. SILVA, Wagner. R. Gramática no texto injuntivo: investigando o impacto dos PCN. Dissertação (Mestrado) - Instituto de Estudos da Linguagem/Departamento de Lingüística Aplicada, UNICAMP, Campinas, 2003.
Subvertendo a exclusão escolar: a mediação como via para a aprendizagem e o desenvolvimento do aluno. Revista Portuguesa de Educação, Universidade do Minho, Centro de Estudos em Educação e Psicologia, v. 18, n. 2, p. 215-239, 2005.

VIGOTSKI, Lev S. Aprendizagem e desenvolvimento intelectual na idade escolar. In: VIGOTSKI, Lev S.; LURIA, Alexander R.; LEONTIEV, Alexei. N. Linguagem, desenvolvimento e aprendizagem. 8. ed. São Paulo: Ícone, 2001a. p. 103-142.

A construção do pensamento e da linguagem. São Paulo: Martins Fontes, 2001b.

A formação social da mente. 6. ed. São Paulo: Martins Fontes, 2003.

WAGNER RODRIGUES SILVA, doutor em lingüística aplicada ao ensino de língua materna pelo Instituto de Estudos da Linguagem da Universidade Estadual de Campinas (IEL/ UNICAMP), é professor adjunto da Universidade Federal do Tocantins (UFT), atuando no curso de letras, no campus Araguaína. Últimas publicações: Marcas gramaticais nas seqüências injuntivas: estratégias de tematização (Revista Humanidades - série Letras, São João da Boa Vista, Fundação de Ensino Octávio Bastos, n. 3, p. 51-64, 2003); Gêneros instrucionais no livro didático: uma proposta para o letramento (Revista Leia Escola, Campina Grande, Universidade Federal de Campina Grande; Idéia, p. 41-52, 2003); O gênero instrução de uso enquanto objeto de ensino (Revista Intercâmbio, Pontifícia Universidade Católica de São Paulo, Lingüística Aplicada e Estudos da Linguagem, Seção: Linguagem e educação, v. XIII, 2004. CD-ROM); Gramática ou análise lingüística: abrindo a "caixa-preta" dos PCN (Revista Estudos Lingüísti$\cos$, São Paulo, Universidade de São Paulo, Grupo de Estudos Lingüísticos, v. 33, 2004. CD-ROM); A prática de análise lingüística no livro didático: uma proposta pós-PCN (Trabalhos em Lingüística Aplicada, Campinas, IEL/UNICAMP, v. 43, n. 1, p. 3549, 2004); Subvertendo a exclusão escolar: a mediação como via para a aprendizagem e o desenvolvimento do aluno (Revista Portuguesa de Educação, Universidade do Minho, Centro de Estudos em Educação e Psicologia, v. 18, n. 2, p. 215-239, 2005). Pesquisa atual: "Tensões na formação profissional do professor de língua materna”.E-mail: wagnerodriguesilva@yahoo.com

Recebido em abril de 2005 Aprovado em maio de 2006 
Wagner Rodrigues Silva

\section{Subversão da exclusão escolar via mediação em atividade de produção textual}

$\mathrm{O}$ artigo analisa o trabalho de mediação realizado pelo pesquisador durante uma atividade de reescrita de uma notícia por um aluno de uma $6^{\mathrm{a}}$ série

projeto, caracterizada como fracassada pela visão fatalista da comunidade escolar. Investiga, desse modo, as possíveis implicações da assunção da noção de gênero discursivo como instrumento semiótico de mediação para o processo de aprendizagem e desenvolvimento. A fundamentação teórica para a investigação realizada é oriunda basicamente de duas áreas de conhecimento: psicologia da educação e estudos da linguagem. Os resultados da pesquisa mostram as possibilidades de subversão da exclusão escolar através da mediação em atividade de produção textual.

Palavras-chave: gênero discursivo; letramento; reescrita;

sociointeracionismo

\section{Textual production as a means of subverting school exclusion}

The article analyses the work of mediation carried out by the researcher during an activity of rewriting a news item by a student of a $6^{\text {th }}$ grade project, labelled as a failure according to the fatalistic vision of the school community. Thus, it investigates the possible implications of the assumption of the notion of the discursive genre as a semiotic instrument of mediation for the learning and development process. The theoretical framework for the investigation derives from two fields of knowledge: educational psychology and language studies. The results of the research reflect the possibilities of subverting school exclusion through the mediation of activities of textual production.

Key words: discursive genre; literacy; rewriting; socio-interactionism

Subversión de la exclusión escolar por la mediación en la actividad de producción textual

El artículo analiza el trabajo de mediación realizado por el encuestador durante una actividad de rescrita de una noticia por un alumno de un $6^{\circ}$ año proyecto, caracterizado como fracasado por la visión fatalista de la comunidad escolar. Investiga de ese modo, las posibles implicaciones de la asunción de la noción de género discursivo como instrumento semiótico de mediación para el proceso de aprendizaje y desenvolvimiento. La argumentación teórica para la investigación realizada es oriunda básicamente de dos áreas de conocimiento: psicología de la educación y estudios del lenguaje. Los resultados de la encuesta muestran las posibilidades de subversión de la exclusión escolar a través de la mediación en actividad de producción textual.

Palabras claves: género discursivo; letramiento; rescrita; sociointeraccionismo 